\title{
BATIK MEGA MENDUNG SEBAGAI IDE PERANCANGAN KEMASAN
}

\author{
Farid Abdullah' ${ }^{1}$, Menul T. Riyanti ${ }^{2}$, Suhaila bt. Basar ${ }^{3}$, Bandi Sobandi ${ }^{4}$, Dian Rinjani ${ }^{5}$ \\ ${ }^{1,4}$ Departemen Pendidikan Seni Rupa, Universitas Pendidikan Indonesia \\ ${ }^{2}$ Desain Komunikasi Visual, Universitas Trisakti \\ ${ }^{3}$ Graphic Programme, Politeknik Ibrahim Sultan, Johor, Malaysia \\ ${ }^{5}$ Program Studi Pendidikan Multimedia, Universitas Pendidikan Indonesia \\ farid.abdullah@upi.edu ${ }^{1}$
}

\begin{abstract}
Abstrak
Permasalahan kemasan (packaging) pada saat ini berkait erat dengan masih rendahnya pemahaman produsen dalam membuat kemasan yang mampu mengangkat nilai isi produk di dalamnya. Bahkan masih banyak produk berkualitas yang belum dikemas secara baik, kurang estetik, dan mampu menjelaskan isi produk dengan memadai. Potensi budaya setempat seperti motif batik, juga masih berjalan sendiri dan belum banyak diangkat menjadi bagian dari suatu kemasan. Motif batik Mega Mendung, Cirebon sudah menjadi ikon motif batik Jawa Barat adalah satu motif yang dapat diangkat menjadi bagian dari kemasan. Tulisan ini memakai metode deskriptif-kualitatif untuk menciptakan kemasan sesuai potensi daerah Trusmi, Cirebon, Jawa Barat. Temuan dari tulisan ini adalah suatu produk yang didesain kemasan secara estetis dan ergonomis, memudahkan pembeli dalam mengenal budaya setempat menjadi lebih baik.
\end{abstract}

Kata Kunci: batik, desain, ide, kemasan, Mega Mendung

\begin{abstract}
The problem of packaging at this time is closely related to the minor understanding of producers in making packaging that can lift the value of the contents of the product. There are still many quality products that have not the package properly, limited aesthetic, and can't be able to explain the contents of the product adequately. Potential of local culture such as batik motifs, also still run by themselves, and not many have designated as part of a package. Mega Mendung, Trusmi, Cirebon batik pattern has become an icon of West Java batik pattern that delegated as part of the package medium. This paper uses a descriptive-qualitative method to create packaging according to the regional potential of the Trusmi, Cirebon, West Java region. The findings of this paper are a product that designed aesthetically and ergonomically designed, making it easier for buyers to get to know the local culture better.
\end{abstract}

Keywords: batik, design, idea, Mega Mendung, packaging 


\section{PENDAHULUAN}

Salah satu permasalahan pada produk-produk yang dihasilkan oleh UMKM (Usaha Mikro, Kecil, dan Menengah) Indonesia adalah persaingan dengan produk luar seperti Cina, Jepang, Thailand, Malaysia, dan Singapura, yang memiliki kemasan (packaging) lebih menarik. Saat ini di Indonesia terdapat kurang lebih 12 juta UMKM, dengan kualitas produk yang mampu bersaing, namun kurang mampu menarik minat konsumen untuk membeli karena dikemas dengan buruk (Syamsudin, 2015). Hasil kajian Pemasaran Produk UKM menunjukkan masih banyak pelaku UMKM Indonesia yang belum memenuhi standarisasi kualitas produk dan kemasan (Kemenkop, 2010). Kondisi ini membuat daya saing produk lokal sangat rendah jika dibandingkan dengan produk luar.

Permasalahan kemasan juga terkait dengan perbedaan budaya. Kesadaran terhadap pentingnya kemasan pada setiap negara berbeda-beda, dan membuat posisi kemasan produk Indonesia masih rendah dalam persaingan. Banyak pertimbangan di balik adanya suatu kemasan seperti ukuran, bentuk, bahan, warna, teks, hingga merek produk (Rundh, 2013). Perbedaan ini kemudian juga mempengaruhi inisitif usaha atau UMK untuk mendesain kemasan yang dimilikinya (Ahmad, Mohibillo, Lakhan, 2012). Sesungguhnya kemasan adalah bagian penting karena berfungsi tidak hanya sebagai pelindung terhadap produk, tetapi kemasan juga sebagai media promosi untuk memikat konsumen berikutnya. Melalui kemasan, banyak konsumen berkeputusan untuk melakukan pembelian terhadap suatu produk (Susetyarsi, 2012). Tampilan kemasan suatu produk memberikan pengaruh bagi konsumen, karena melalui kemasan maka pesan dari isi produk di dalamnya, baik melalui tulisan informasi, maupun tampilan suatu kemasan yang memberi citra bagi konsumen (Apriyanti, 2018).

Potensi budaya Indonesia sangat berlimpah dan belum tergali secara optimal. Potensi ini meliputi kualitas produk, hingga unsur budaya seperti ornamen yang berlimpah di setiap daerah. Salah satu potensi berlimpah tersebut adalah motif batik. Ornamen atau motif batik sangat berlimpah dan terus dikembangkan pada berbagai media. Penerapan ornamen batik tidak terbatas pada sehelai kain, akan tetapi pada berbagai media lain seperti salut kursi (upholstery), kertas, batik kayu, dan lainnya. Penerapan motif tidak dibatasi oleh teknik produksi seperti batik tulis, cap, ataupun gabungan. Kesemuanya menunjukan tujuan yang sama yaitu untuk melestarikan nilai-nilai budaya bangsa (Wardani \& Sitindjak, 2014).

Cirebon adalah daerah penghasil batik dengan sentra Trusmi sebagai pusat produksinya. Batik Trusmi, Cirebon termasuk dalam batik pesisir dalam konstalasi batik Indonesia, namun demikian sebagian batik Cirebon masuk sebagai bagian dari batik keraton karena keberadaan Keraton Kasepuhan, Keraton Kanoman, Keraton Kacirebonan dan Keraton Kaprabonan. Keberadaan keraton-keraton ini yang mendorong terciptanya desain motif batik klasik Cirebonan seperti Mega Mendung, Paksi Naga Liman, Patran Keris, Patran Kangkung, Singa Payung, Singa Barong, Banjar Balong, Ayam Alas, Sawat Penganten, Katewono, Gunung Giwur, Simbar Menjangan, Simbar Kendo (Arwanto, 2017). Potensi kekayaan motif batik klasik ini dapat diolah pada media-media baru, termasuk kemasan. 
Motif batik Mega Mendung berkait erat dengan sejarah panjang batik Cirebon. Keberadaan batik Cirebon sebagai suatu industri kerajinan rakyat telah ditelusuri keberadaannya sejak akhir abad-19 atau awal abad ke-20. Sejarah batik Cirebon telah tercatat hingga masa Kerajaan Cirebon di abad ke-14 (Prasetyaningtyas, 2011). Memahami sejarah panjang batik Cirebon, maka modalitas sejarah panjang ini dapat menjadi peluang untuk terus dihidupkan (preserve). Peningkatan ekonomi wilayah Cirebon juga dapat didukung oleh penciptaan kemasan yang bercirikan artefak lokal seperti motif Mega Mendung.

\section{METODE PENELITIAN}

Penelitian ini adalah penciptaan kemasan dengan memakai pendekatan deskriptif kualitatif. Menurut Sumartono, metode deskriptif bertujuan memaparkan kondisi yang ada untuk kemudian menguraikannya. Konsep deskriptif dapat diterapkan dalam penelitian bahasa rupa, seni, dan desain dengan syarat bahwa topik penelitian menyangkut observasi pada obyek yang diteliti (Sumartono, 2018: 13), sedangkan pendekatan kualitatif bersifat fleksibel dan luwes berdasarkan kondisi lapangan, dengan pengambilan data berupa interview dan dokumentasi di lapangan (Sarwono, 2007).

\section{PEMBAHASAN}

Kemasan adalah bagian dari bidang praktis dan pragmatis keilmuan desain. Pengertian luas desain terdiri atas: (1) Metode perancangan prosedur dan proses; (2) Konsep nilai yang terkandung dalam konten desain terkait identitas dan makna; (3) Artefak yang mencakup media dan fungsi desain (Budiwaspada, 2017). Kemasan adalah satu bidang kajian dalam desain komunikasi visual yang mempunyai tuntutan khusus karena fungsinya yang langsung berhadapan dengan konsumen, antara lain tuntutan teknis, kreatif, komunikatif, dan pemasaran yang harus diwujudkan ke dalam bahasa visual (Amri, 2016: 165). Maka peran desainer dalam menciptakan kemasan adalah bagian dari pemecah masalah untuk mampu bersaing di era perdagangan bebas saat ini.

Perancangan desain kemasan memiliki suatu metode dan prosedur dasar (Li, Yao, Song, 2014). Pada setiap perancangan kemasan modern terdapat tahapan dan metode desain yang mengiringinya. Setiap tahapan saling terkait erat dan sangat berhubungan dan merupakan cara untuk berhasil dalam merancang kemasan produk ideal. Penentuan posisi desain tunduk pada tautan prosedur pembuatan kemasan. Oleh karena itu, persyaratan prosedural dasar dari desain kemasan harus dipahami seperti bagan di bawah ini (Gambar 1). 


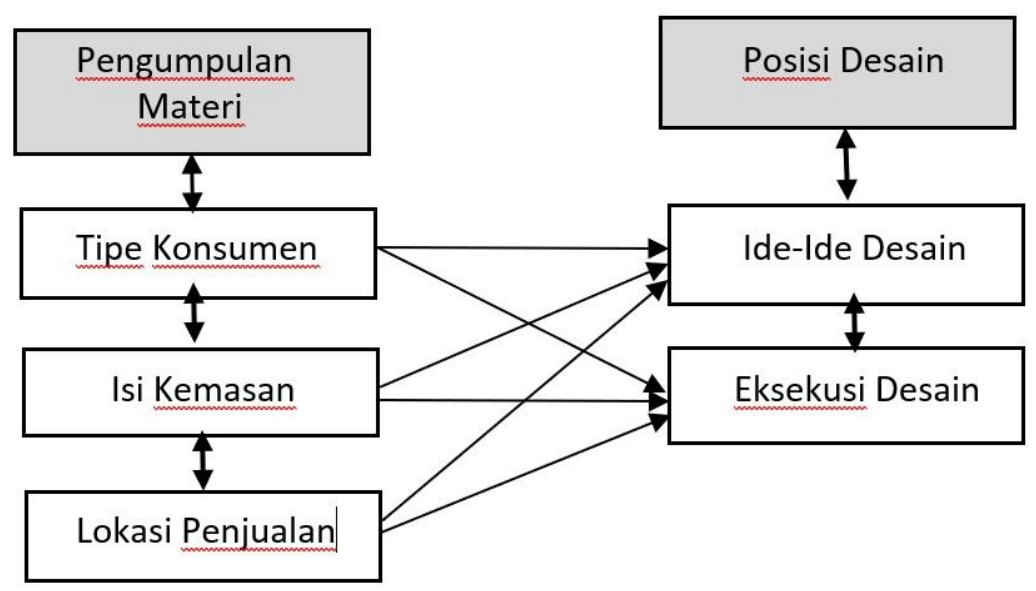

Gambar 1. Bagan Prosedur Dasar Desain Kemasan

[Sumber: diolah dari Li, Yao, \& Song, 2014]

Pada bagan di atas, secara umum prosedur dasar perancangan desain kemasan modern terbagi atas dua bagian utama yaitu: pengumpulan materi dan memposisikan desain. Pada bagian pengumpulan materi dilakukan data collecting seperti: karakteristik motif Mega Mendung, tipe konsumen yang dituju, isi kemasan, serta lokasi penjualan produk kemasan. Sedangkan pada bagian posisi desain adalah proses mengeluarkan ide-ide desain hingga eksekusi desain.

\subsection{Pengumpulan Materi}

Motif Mega Mendung secara visual memiliki komposisi warna berupa gradasi yang mencapai 9 hingga 11 nuansa gradasi warna (Djoemena, 1990: 38). Banyaknya jumlah gradasi warna ini menjadi pembeda dengan motif-motif batik lainnya. Pada motif batik lainnya, dapat dikatakan tidak terdapat motif yang memiliki gradasi warna sebanyak Mega Mendung. Gradasi warna biru menjelaskan tentang awan gelap yang mengandung air hujan dan bermakna memberi penghidupan. Warna biru muda menggambarkan harapan akan semakin cerahnya kehidupan (Prasetyo, 2010).

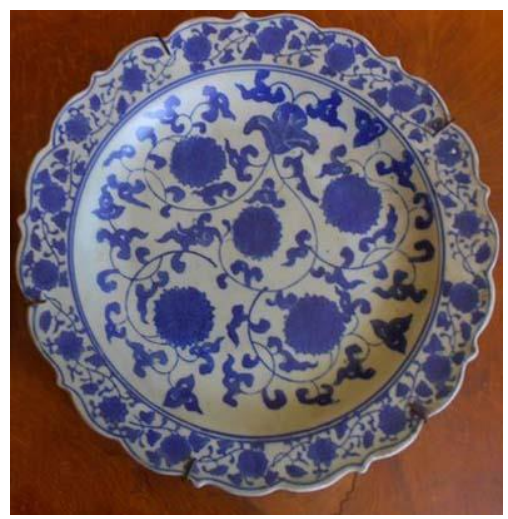

[a]

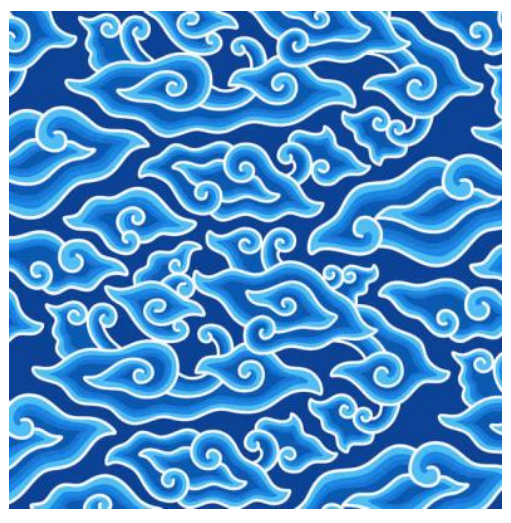

[b]

Gambar 2. [a] Keramik Cina Era Dinasti Ming di Cirebon; [b] Motif Mega Mendung. [sumber: Prasetyaningtyas, 2011] 
Merunut latar budayanya, motif Mega Mendung merupakan pengaruh budaya Cina yang erat di lingkup Cirebon sebagai kota pelabuhan. Sumber lain juga menyatakan bahwa warna motif Mega Mendung memiliki kemiripan dari motif keramik Cina yang banyak terdapat di lingkungan keraton Cirebon. Warna-warna gradasi biru muda menunjukan kesamaan tinggi dengan warna keramik-keramik pada Dinasti Ming (Rasjoyo, 2008). Benang merah kesamaan dan pengaruh budaya Cina ini menjadi pengembangan dasar dari motif Mega Mendung.

Dinasti Ming berkuasa di Cina pada tahun 1368 hingga 1644 Masehi. Kebudayaan Cina di bawah Kaisar Hongwu mencapai puncak kemasyhuran dan banyak melakukan ekspedisi-ekspedisi ke negara lain di Asia, termasuk Cirebon. Ekspedisi yang sangat terkenal dipimpin oleh Laksamana Cheng Ho. Ekspedisi dilakukan sebanyak 7 kali menjelajak ke Asia Tenggara, India, Jazirah Arab, hingga pesisir timur Afrika dari tahun 1405 hingga 1433 Masehi. Salah satu produk yang dibawa oleh ekspedisi ini adalah keramik-keramik dari Cina untuk dilakukan barter dengan produk daerah yang dikunjunginya, termasuk Cirebon (Jasmerah, 2014). Interaksi budaya Cina dan Cirebon kemudian terwujud dengan penciptaan batik Mega Mendung sebagai bentuk relasi budaya antara keduanya.

\subsection{Tipe Konsumen}

Tipe konsumen yang dikaji dalam tulisan ini adalah konsumen menengah dan atas. Tipe konsumen menengah dan atas ini berdasarkan amatan pada sentra batik Trusmi Cirebon banyak melakukan pembelian produk-produk batik Trusmi, Cirebon. Pembelian semakin meningkat ketika menjelang Hari Raya seperti Ramadhan dan saat liburan sekolah. Tipe konsumen menengah dan atas memiliki daya beli yang tinggi dan secara berkala melakukan transaksi pembelian di sentra Batik Trusmi Cirebon.

Tipe konsumen yang memperlihatkan keputusan membeli di sentra batik Trusmi, Cirebon, banyak dilakukan oleh kaum wanita. Tipe konsumen di dominasi wanita remaja maupun wanita dewasa dibandingkan kaum pria. Keputusan membeli yang didominasi wanita ini juga banyak ditemui pembelian oleh wanita untuk pasangannya yaitu ditujukan untuk suami ataupun anak-anak. Hal ini (tanda panah pada bagan Gambar 1) berhubungan erat dengan isi kemasan, yaitu produk batik.

\subsection{Isi Kemasan}

Isi kemasan adalah produk-produk batik yang diperjualbelikan di Sentra Batik Trusmi, Cirebon. Produk-produk yang diperjualbelikan di sentra batik Trusmi, Cirebon antara lain berupa baju atasan, topi, ikat kepala, bawahan seperti rok, celana panjang, hingga sandal bermotif batik. Produk batik lainnya juga diperjualbelikan seperti, dompet, tas, hiasan dinding, hingga perlengkapan rumah tangga seperti seprai, sarung bantal, dan sejenisnya. Aneka produk batik tersebut dapat dikelompokan pada busana dan non busana atau pelengkap busana.

Secara umum, menurut interview dengan Ibu Anisah (58 tahun) pemilik usaha batik Trusmi, Cirebon, produk batik yang paling banyak dibeli adalah baju atasan, kain batik, 
dan pelengkap busana seperti dompet, tas batik. Untuk baju batik atasan, banyak juga terjadi transaksi berupa busana berpasangan, sarimbit, untuk satu keluarga yang terdiri dari suami, istri, dan anak-anak.

\subsection{Lokasi Penjualan}

Lokasi penjualan adalah desa Trusmi, Kabupaten Cirebon. Sentra batik Trusmi, Kabupaten Cirebon memiliki unit produksi yang berada di belakang toko-toko tersebut. Menurut catatan kantor dinas Departemen Perindustrian dan Perdagangan Jawa Barat, Sentra Batik Trusmi melibatkan sekitar 1.102 jiwa pada tahun 2011 (Disperindag Kab. Cirebon, 2012). Lokasi ini terhitung strategis karena berada di perbatasan Jawa Barat dengan Jawa tengah. Untuk menjangkau Desa Trusmi, juga tersedia jalan raya dan jalan tol bebas hambatan yang memudahkan konsumen mendatangi Desa Trusmi, Kabupaten Cirebon, Jawa Barat.

Lokasi penjualan selain di sentra batik Trusmi, Kabupaten Cirebon, juga terdapat tokotoko cabang yang tersebar di kota besar seperti Bandung, Jakarta, Pekalongan, dan Yogyakarta. Toko-toko cabang batik Trusmi ini juga memerlukan kemasan yang menjelaskan tentang produk batik Trusmi kepada konsumen.

\section{Posisi Desain}

Pengertian posisi desain berasal dari kata positioning yang memiliki arti menempatkan produk dan merek dibenak konsumen. Menempatkan produk dan merek dalam benak konsumen sesungguhnya adalah bagian dari perang atau kompetisi pemasaran. Perang pemasaran adalah usaha untuk memperebutkan sejengkal ruang ingat di benak konsumen (Al Ries \& Trout dalam Kartajaya, 2007). Demikian pula kemasan dengan motif Mega Mendung, sesungguhnya berusaha menjadi bagian dari ingatan konsumen akan produk batik Trusmi, Cirebon.

Menempatkan dalam ingatan konsumen menjadi penting, ketika kompetitor dari batik Trusmi, Cirebon juga bersaing ketat untuk menjadi bagian dari ingatan konsumen batik. Kompetitor batik Trusmi antara lain adalah batik Pekalongan, batik Indramayu, batik Solo, batik Garutan, hingga batik Yogyakarta. Maka peran kemasan agar menjadi komponen memenangkan perang positioning menjadi sangat penting. Peran kemasan maka menjadi sangat penting agar memiliki tempat pada benak calon konsumen batik. Ketika produk batik dan kemasan dibeli konsumen dan berjalan ke tujuan tempat tinggal konsumen, maka kemasan dapat menjadi sarana promosi berjalan bagi calon konsumen baru.

\subsection{Ide-Ide Desain}

Tahap ide-ide desain dalam perancangan ini berawal pada motif batik Mega Mendung sebagai tema utama (subject matter) kemasan. Tahap ini mendapat masukan data dari tipe konsumen, isi kemasan, dan lokasi penjualan (tanda panah $\leftrightarrow$ pada gambar 1 ). Mencermati tipe konsumen dominan kaum wanita, baik remaja maupun dewasa, maka ide yang dapat ditawarkan adalah pilihan aneka warna, sebagai alternatif terhadap kemasan yang akan dirancang. Tipe konsumen wanita memiliki kecenderungan memilih 
warna-warna yang feminin, lembut, namun juga dinamis. Pada perancangan ini, warna alternatif diajukan yaitu: (a) gradasi biru; (b) gradasi abu-abu; (c) gradasi merah marun; (d) gradasi hijau; dan (e) gradasi ungu seperti gambar 3 di bawah ini.

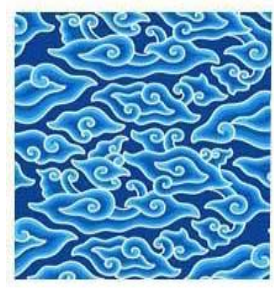

(a)

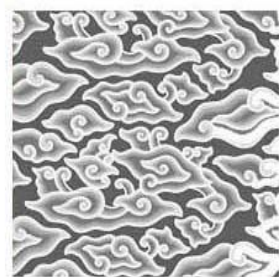

(b)

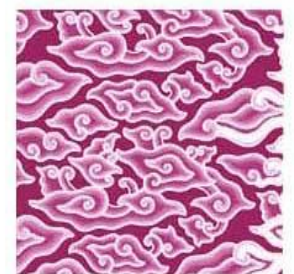

(c)

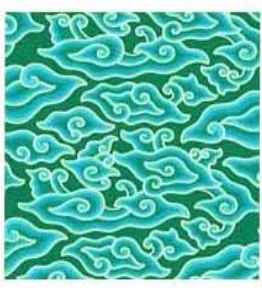

(d)

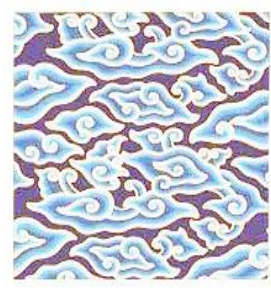

(e)

Gambar 3. Alternatif Warna Motif Mega Mendung [Karya: Faiza Roikhatuzahra, 2020]

Pada gambar 3 di atas, sejumlah alternatif ide-ide berupa pilihan warna motif batik Mega Mendung. Ide-ide berupa pilihan warna dasar biru tua, abu-abu, merah marun, hijau, dan ungu juga terkait dengan produk batik yang banyak dihasilkan di sentra batik Trusmi, Cirebon.

Ide desain pada kemasan batik Trusmi, Kabupaten Cirebon terkait juga dengan lokasi penjualan yaitu desa Trusmi. Pada lokasi penjualan, memasuki sentra Trusmi terdapat gerbang megah yang didominasi material batu bata. Gerbang masuk ini juga ditemui serupa dengan gerbang pada keraton Kasepuhan, Cirebon. Gerbang berbahan batu bata ini di dominasi warna merah marun yang dapat dieksplorasi menjadi bagian dari kemasan batik Trusmi, Cirebon.

\subsection{Eksekusi Desain}

Berikut ini adalah eksekusi desain, sebagai bagian perancangan kemasan untuk sentra batik Trusmi, Cirebon. Eksekusi desain adalah rancangan yang dapat dilakukan produksi menjadi benda jadi. Eksekusi desain memiliki relasi (tanda panah $\leftrightarrow$ pada gambar 1 ) dengan tipe konsumen, isi kemasan, lokasi penjualan dan posisi desain.

Tipe konsumen untuk perancangan kemasan Trusmi, Cirebon, dipertajam pada konsumen kelas menengah dan atas. Tipe konsumen ini juga mempertimbangkan dominasi wanita sebagai pengambil keputusan dalam pembelian. Isi kemasan untuk kemasan batik Trusmi, Cirebon, spesifik berupa produk-produk busana batik, seperti baju atasan, bawahan, kemeja, hingga kain batik. Isi kemasan berupa produk batik yang dapat dilipat dan dimasukan ke dalam kemasan.

Maka desain rancangan untuk kemasan batik Trusmi, Cirebon ditampilkan sebagai berikut: 


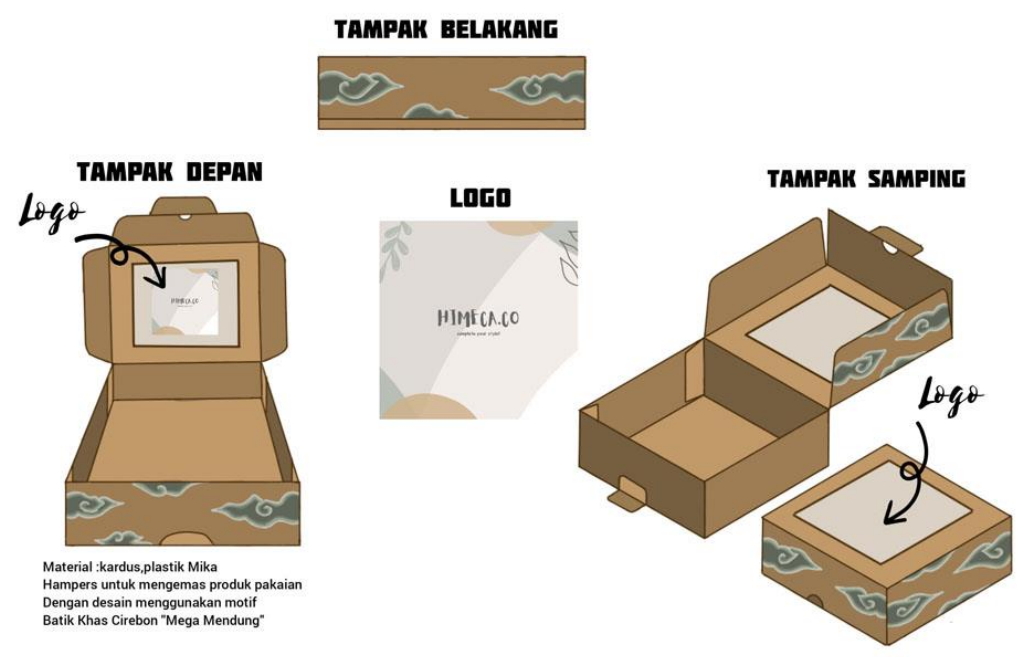

Gambar 4. Desain Kemasan Motif Mega Mendung

[Karya: Faiza Roikhatuzahra, 2020]

Pada desain kemasan di atas, materi yang dipakai adalah kardus kertas karton corrugated, dan hampers kertas untuk mengemas produk isi. Pada bagian samping kiri dilengkapi dengan keterangan singkat filosofi motif Mega Mendung, nilai-nilai yang terkandung, serta sejarah singkat batik Trusmi Cirebon. Ukuran dimensi kemasan adalah lebar $30 \mathrm{~cm}$ x panjang $40 \mathrm{~cm} \times$ tinggi $6 \mathrm{~cm}$. Pertimbangan dimensi kemasan adalah memudahkan penyimpanan produk batik seperti baju, celana, $t$-shirt, hingga kain batik.

Kemasan juga harus berbahan yang mudah di daur ulang, seperti karton kertas ramah lingkungan. Penggunaan kertas karton lebih mudah diurai olah tanah, jika dibandingkan plastik. Hal ini sejalan dengan program dunia yaitu pengurangan bahan plastik. Pembungkus kemasan dapat memakai tas berbahan kertas ramah lingkungan. Pada tas berbahan kertas ramah lingkungan juga dilengkapi motif batik Mega Mendung sebagai informasi penjelas dari isi. Pada tas tersebut juga memiliki keterangan yang serupa dengan kemasan.

\section{KESIMPULAN}

Potensi ragam hias Indonesia sangat besar, termasuk Mega Mendung untuk diangkat ke dalam format-format baru. Memasukan motif batik Mega Mendung menjadi bagian satu kemasan, disertai informasi tentang filosofi, nilai-nilai serta makna yang terkandung di baliknya pada kemasan, dapat mengangkat artefak batik dan wilayah Trusmi, Cirebon itu sendiri. Kemasan yang baik dan estetis, dapat menjadi promosi berjalan yang dibawa oleh konsumen ke tempat asal dan menjadi informasi penting bagi konsumen berikut.

Perancangan kemasan yang baik adalah konsekuensi dari kompetisi komoditas pasar. Untuk dapat bersaing dengan produk-produk luar negeri yang telah dikemas dengan baik, desain memegang peranan penting dalam mendukung penjualan produk itu sendiri. Besar kemungkinan produk batik Indonesia pun dapat berkompetisi di luar negeri apabila di kemas dengan standar tinggi dan estetis. Pada akhirnya dapat 
mengangkat derajat ekonomi UKM Trusmi, Cirebon dan seluruh sumber daya manusia di sekitarnya.

\section{DAFTAR PUSTAKA}

Ahmad, M., Lakhan. (2012). Effect of Product Packaging in Consumer Buying Decision, Journal of Business Strategies, 6(2), 1-10.

Amri, A. (2016). Model Penelitian Desain Komunikasi Visual. Bekasi, PT. Cakra Press.

Apriyanti, M.E. (2018). Pentingnya Kemasan Terhadap Penjualan Produk Perusahaan, Jurnal Sosio e-Kons, 10(1), 20-27.

Arwanto. (2017). Eksplorasi Etnomatematik Batik Trusmi Cirebon untuk Mengungkap Nilai Filosofi dan Konsep Matematis, Phenomen: Jurnal Pendidikan Matematika dan Ilmu Pengetahuan Alam, 7(1), 40-49.

Budiwaspada, A.E. (2017). Desain dan Media sebagai Instrumen Nation Branding, Seminar Nasional Desain dan Media, 22 Oktober 2017, LPMP, Universitas Indraprasta, Jakarta.

Djoemena, S.N. (1990). Ungkapan Sehelai Batik: Its Mystery and Meaning. Penerbit Djambatan, Jakarta.

Dinas Perindustrian dan Perdagangan, Kabupaten Cirebon, Jawa Barat. (2012). Laporan Potensi Industri dan Perdagangan, Kabupaten Cirebon, Jawa Barat.

Dinasti Ming. (2014). Jasmerah: Majalah Sejarah Online\#5, Feb-Mar. https://www. academia.edu/40496553/_005._Jasmerah_Februari-Maret_2014_-_DINASTI _MING (diakses pada 8 Juli 2020).

Kartajaya, H. (2007). Boasting Loyalitas Marketing Performance. PT. Mizan Pustaka, Bandung.

Kemenkop., (2010). 79,41 persen UKM Pangan Tanpa Label, http://www.depkop .go.id/index.php?option=com_content\&view=article\&id=466:kemenkop-941persen-ukm-pangan-tanpa-label\%catid=50:bind-berita\&ltemid=97. (diakses pada 7 Juli 2020).

Li, Y., Yao, K., \& Song, C. (2014). Study on Packaging Design Positioning and Method Based on Design Accuracy. Journal of Chemical and Pharmaceutical Research, 6(3), 885-889.

Prasetyaningtyas. (2011). Perkembangan Motif dan Warna Batik Mega Mendung di Kawasan Sentra Batik Trusmi, Cirebon, Jawa Barat, skripsi Program Studi Pendidikan Seni Kerajinan, Fakultas Bahasa dan Seni, Universitas Negeri Yogyakarta.

Prasetyo, A. (2010). Batik: Karya Agung warisan Budaya Dunia. Pura Pustaka, Yogyakarta.

Rasjoyo. (2008). Mengenal Batik Tradisional, Azka Press, Jakarta.

Roikhatuzahra, F. (2020). Desain Packaging Motif Mega Mendung Cirebon, Jawa Barat, tugas kuliah, tidak dipublikasikan, mata kuliah Kajian Ornamen Nusantara, Pendidikan Seni Rupa, Universitas Pendidikan Indonesia.

Rundh, Bo. (2013). Linking Packaging to Marketing: How Packaging is Influencing the Marketing Strategy. British Food Journal, 115(11), 1547-1563.

Sarwono, J. \& Lubis, H. (2007). Metode Riset untuk Desain Komunikasi Visual, Yogyakarta, CV. Andi offset. 
Sumartono. (2017). Metodologi Penelitian Kualitatif Seni Rupa dan Desain. Pusat Studi Reka Rancang Visual dan Lingkungan, Fakultas Seni Rupa dan Desain, Universitas Trisakti, Jakarta.

Susetyarsi, T. (2012). Kemasan Produk Ditinjau dari Bahan Kemasan, Bentuk Kemasan dan Pelabelan pada Kemasan Pengaruhnya terhadap keputusan Pembelian Pada Produk Minuman Mizone di Kota Semarang, Jurnal STIE, 4(3), 19- 28.

Syamsudin, Wajdi, F., Praswati, A.N. (2015). Desain Kemasan Makanan Kub Sukarasa di Desa Wisata Organik Sukorejo Sragen, BENEFIT: Jurnal Manajemen dan Bisnis, 19(2), 181-188.

Wardani, L.K., Sitindjak, R.H.I. (2014) Batik and Its Implementation in Art and Design, The International Journal of Social Sciences, 24(1), 37-44. 